\title{
Discussion on Network Multimedia Application in Vocal Music Teaching under the Internet
}

\author{
Jie Zhao \\ Jiangxi Teachers College, Jiangxi, Yingtan, China, 335000
}

Keywords: Internet; Multimedia Applications; Vocal Music Teaching

\begin{abstract}
Vocal music can cultivate people's sentiments, soothing people's physical and mental, and a correct and effective vocal music teaching can achieve the students outlook on life, world view, values, the correct guidance, and training students singing habits, so that students become a multi- talent. However, Chinese vocal music teaching system is not perfect and the lack of intuitive teaching makes the development of vocal music in China into a bottleneck. But with the advent of the information age, it has brought new opportunities to our vocal music teaching. This paper starts from the influence of multimedia on the music culture in our country, and finds out the difficulties in the development of multimedia applications in vocal music teaching in China and gives the corresponding solutions.
\end{abstract}

\section{Introduction}

With the in-depth development of Internet technology, greatly facilitate people's lives, but also on Chinese education sector has brought new opportunities. In this network technology road under the social background, multimedia network technology gradually penetrates into the daily teaching activities have become an auxiliary teaching means. In the course of vocal music teaching, the use of multimedia technology and tools can change the state of students' vocal music, from the traditional single state to the auditory system and other sensory systems to accept the system change, thus forming a new type of vocal music teaching mode, and teachers in carrying out this special teaching mode, effectively enhance the students in the learning process of interaction, compared to the traditional teaching methods more easily stimulate students interest in learning, breaking the current vocal teaching bottlenecks, promote our vocal music teaching innovation.

\section{The Status of Vocal Music Teaching}

With the continuous improvement of Chinese social and economic level, Chinese citizens continue to improve their lives, people pay more and more attention to the enjoyment of life, so the atmosphere of music development in recent years, unprecedented high, so a variety of music-related entertainment programs by people of the popular, followed by the popular there are high school vocal professional. Vocal music teaching as the most difficult subject of music subjects, he is different from other music disciplines, it is in the process of learning is usually used in the teaching method is more abstract, so a certain degree of lying that increased the difficulty of teaching. From the current society of our country for the vocal music teaching situation, although there are many people optimistic about the vocal professional this way out, but few people can really understand the people but only a few. Which also led to the current vocal music teaching quality of the current, but still follow the traditional teaching methods, this approach is not only a waste of time, and efficiency is not high. Although Chinese network technology is more and more developed, applied to the field of music in the multimedia technology is also a minority, but in the vocal music teaching is still not popular [1]. 


\section{The Impact of Multimedia on Music Culture}

In the case of multimedia applications continue to strengthen the situation, so that Chinese traditional music culture has begun to change, the realization of multimedia so that our culture from the book culture inheritance to digital heritage. The following points on the impact of multimedia on the music culture to study.

Make Teaching Resources Become Broad. In our country's music culture teaching idea, mainly teachers around the books to teach students, however, teaching materials have limitations, to a certain extent, so that students learn music content is limited, multimedia, teachers can use multimedia selection A variety of music teaching resources to teach students, some of the latest research music trends and results can also be used as a reasonable teaching resources into the teaching, so that students grasp the content closely follow the development of the times [5]. In addition, in the classroom teaching, due to limited time, more students, music teachers cannot every one of the students to explain the one-on-one details, easily lead to some students fuzzy knowledge or knowledge difficult to understand the situation, long-term In the past, students have no reasonable knowledge of the knowledge point, it will lead to the decline in student achievement, affecting the enthusiasm of students to learn [6]. After the realization of multimedia, students can use their spare time to choose their own teaching resources, the teaching of the knowledge learned to effectively consolidate, multimedia can help students to one-on-one voice, the image of the detailed explanation, so that students in teaching. The question can be dealt with rationally, at the same time, students can also according to their own interests and so on, the use of multimedia selection of the relevant music teaching content, both to enrich the students 'spare time and cultivate the students' expertise [2].

Promote Students to Develop A Good Learning Habit. In our country's music culture teaching, the communication time among the students is generally too little. According to the survey, most students only have good relations with their friends, and some of the more remote students are less and others. Students to study and exchange between students from school every day to go home or dormitory [7]. We often say that the long complement of 100 is short, due to the lack of communication time and space, so that students cannot be good between each other to learn. The realization of multimedia, which greatly promoted the use of spare time between students for music and cultural exchanges, so that the characters are more remote or not good at the expression of students can also participate in the exchange process, according to other students better learning methods and then continue to combine their own problems are not perfect, not only enriched the students to learn music culture, but also to promote the good friendship between students, so that students can grow up healthy.

\section{The Problems of Multimedia Technology in the Vocal Music Teaching}

With the improvement of people's living standard, people's material enjoyment and spiritual enjoyment level also gradually increased, therefore, in order to pursue more efficient service, many people break the routine, keep up with the trend of the times, in the development of innovation, the full use of modern scientific and technological means stand up. It is to promote the development of Chinese music has played a crucial role. However, there are still some problems in the application of multimedia technology to practical courses [3].

Vocal Music Teacher Is Not Skilled at the Use of Multimedia Technology. In the current social environment, Chinese vocal music teaching for the application of multimedia is not widely available in colleges and universities, largely because vocal music teachers are not skilled in the use of multimedia technology. The main reason for this is two, the first is because in the current college music teaching, vocal music is a more difficult subjects, therefore, on the vocal music teacher is often older, with rich teaching experience and deep vocals of the old artists, so they learn new business process, often need a long cycle, coupled with limited learning ability, for the new multimedia technology applications cannot be skilled operation which will increase the workload of teachers in the teaching process, reducing the quality of teaching. There is a reason is that teaching 
for the general application of multimedia bias, this type of artist often feel that word of mouth is the only way to learn vocal music, so in many cases for the application of multimedia to vocal music teaching has not been taken seriously, resulting in vocal the multimedia application of teaching is not popular in colleges and universities [4].

Multimedia Vocal Teaching Resources Library Activities Are Old. In Chinese current colleges and universities, the application of multimedia is not very positive, the vast majority of colleges and universities courses still follow the traditional teaching model, although in colleges and universities equipped with multimedia laboratories, but because of university leaders and teachers on the application concept too despise, resulting in college multimedia laboratory abandoned, over time, the University of multimedia resources in the library has not been immediately updated, lost the original function. And for the college multimedia classroom application of the phenomenon of desolation because the university leaders for the application of multimedia to the daily teaching of the concept of no attention, there is a very important factor is that Chinese colleges and universities for the management of multimedia database without special staff maintenance and management, and teachers in colleges and universities have no relevant experience, thus making the university multimedia resource library information lag, which is led to the university multimedia applications in the development of vocal music is one of the important factors hindered.

Multimedia Hardware Facilities Are Not Perfect. In the current social background, want to achieve the application of vocal music multimedia, multimedia hardware facilities has become the key. However, in the major universities in China, although the application of multimedia classrooms in colleges and universities is not universal, even if the school is equipped with multimedia classrooms are only generic, and this classroom is the need for the classroom cannot fully meet the needs of the current vocal music teaching, thus making the vocal music teaching multimedia application has become an empty talk.

\section{The Way to solve the Multimedia Technology in Vocal Music Teaching}

Enhance the Overall Quality of the Classroom. The quality of teachers will directly determine the quality of vocal music teaching, and this teacher is not only the quality of teachers in the professional knowledge of the ability, but also refers to the ability of teachers to learn fresh business. Through the activities of teachers in colleges and universities to engage in vocal music and multimedia activities, active teaching atmosphere, and secondly, the vocal music teachers in colleges and universities to carry out regular training of multimedia knowledge to ensure that teachers in the daily teaching proficient in the use of multimedia tools, this will not only be able to achieve the teacher on the fresh counseling and knowledge of learning, but also speed up the teaching of vocal music in colleges and universities reform. The last is through the training of young teachers, through the young groups to drive other teachers, so as to achieve the active atmosphere of multimedia applications, and young teachers also shoulder the responsibility of the elderly teachers to use the role of multimedia [5].

Use the Vocal Music Practice to Enrich the Vocal Music Teaching Database. Through the specialized organizations in colleges and universities to students usually vocal music teaching and vocal music activities recorded with the camera, made it into the corresponding teaching materials, into the input into the school vocal music teaching database. This can be done to complete and long-term effective preservation of students for vocal learning process. Teachers and students can access this information at any time via a network computer. And students through other people's learning methods and learning attitude to encourage their own vocal learning. And the classroom in the multimedia classroom, through the public screen in the process of screening, students can more intuitive understanding of their own vocal music in the process of learning the wrong place, and this to a large extent to help the classroom to save classroom teaching Time, the classroom can also be through the combination of video in their own theoretical knowledge, making the basics of vocal music easier to accept, so as to improve the efficiency of vocal music teaching. 
Strengthen the Construction of Multimedia Infrastructure in Vocal Music Teaching in Colleges and Universities. Colleges and universities as a base for vocal music teaching, and strengthen the internal vocal music teaching infrastructure is to learn vocal music to promote vocal music of the primary conditions. But from colleges and universities in the vocal music teaching infrastructure construction is not satisfactory. Therefore, in the construction of multimedia vocal music teaching infrastructure, should be done to the contents of the university has a special vocal music teacher and teachers are equipped with a dedicated vocal music teaching database to facilitate the use of teachers in the teaching process. University of multimedia technology construction has a prerequisite, that is, must be highly valued by the school leaders, the only way to allow students to allocate funds in colleges and universities within the construction of multimedia teachers.

\section{Conclusion}

Multimedia technology makes vocal music teaching more vivid, more visual to facilitate students to learn vocal music, give full play to the advantages of network technology to improve the quality of teaching vocal music teaching. With the improvement of people's living standard, people's demand for music has gradually become demanding, the use of the current network technology and multimedia technology means to achieve the innovation of vocal music teaching, and promote the output of our vocal talent, the overall quality of vocal talent, in improving the interest of students at the same time meet the needs of the community of vocal music talent, vocal music students in the future to help win the employment advantage.

\section{References}

[1] Xu Fei. Explore the Internet and network multimedia in vocal music teaching application [J / OL]. Yellow River Voice, 2017, (09): 30-31. (2017-07-19)

[2] Tama Xia Tuo Like Pakistani clothing. Explore the application of multimedia technology in vocal music teaching in colleges and universities [J]. Art Technology, 2017, 30 (01): 382.

[3] Zhang Kedong. Multimedia technology in the use of vocal music teaching and the role[J]. Drama House, 2016, (03): 161.

[4] $\mathrm{Hu}$ Junxian. Vocal music teaching in the application of multimedia teaching technology characteristics and application value[J]. Drama House, 2014, (15): 80.

[5] Wu Fei. Application of multimedia technology in vocal music teaching[J]. Reform and opening, 2014, (12): 79-80. 